\title{
Syndactyly: phenotypes, genetics and current classification
}

\author{
Sajid Malik ${ }^{*}, 1$
}

Syndactyly is one of the most common hereditary limb malformations depicting the fusion of certain fingers and/or toes. It may occur as an isolated entity or a component of more than $\mathbf{3 0 0}$ syndromic anomalies. Syndactylies exhibit great inter- and intra-familial clinical variability. Even within a subject, phenotype can be unilateral or bilateral and symmetrical or asymmetrical. At least nine non-syndromic syndactylies with additional sub-types have been characterized. Most of the syndactyly types are inherited as autosomal dominant but two autosomal recessive and an X-linked recessive entity have also been described. Whereas the underlying genes/mutations for types II-1, III, IV, V, and VII have been worked out, the etiology and molecular basis of the other syndactyly types remain unknown. In this communication, based on an overview of wellcharacterized isolated syndactylies, their cardinal phenotypes, inheritance patterns, and clinical and genetic heterogeneities, a 'current classification scheme' is presented. Despite considerable progress in the understanding of syndactyly at clinical and molecular levels, fundamental questions regarding the disturbed developmental mechanisms leading to fused digits, remain to be answered.

European Journal of Human Genetics (2012) 20, 817-824; doi:10.1038/ejhg.2012.14; published online 15 February 2012

Keywords: syndactyly; syndactyly classification; clinical heterogeneity; genetic heterogeneity; webbed digits

\section{INTRODUCTION}

Syndactyly (Greek $S y n=$ together; Dactylos=digit) is a digital malformation in which adjacent fingers and/or toes are webbed because they fail to separate during limb development. It is one of the most common hereditary limb malformations depicting a prevalence of 3-10 in 10000 births, though higher estimates ranging from $10-40 / 10000$ have been reported. ${ }^{1,2}$

Clinically syndactyly is one of the most heterogeneous developmental deformities known in the medical literature. A number of combinations are possible in which the adjacent fingers and/or toes remain connected by a web. It may be unilateral or bilateral, and symmetrical or asymmetrical. Furthermore, inter- and intra-familial phenotypic variability is quite common. The condition is so variable that the same individual may exhibit asymmetrical phenotypes in the upper and lower, and right and left limbs. Syndactyly can be identified as partial or complete, cutaneous or bony, and involving only the phalanges or further extending up to metacarpal/metatarsal or carpal/ tarsal levels, sometimes even proximating the distal end of forearm/ foreleg. On the minimal extreme, a milder phenotype may only be recognized by the alterations in interphalangeal creases and peculiarities in dermatoglyphics. ${ }^{3}$

Syndactyly may segregate as an isolated clinical phenotype. There are at least nine well-characterized syndactylous entities with subdivisions, the majority of which have non-syndromic nature. Most of these entities segregate in Mendelian dominant fashion. However, two autosomal recessive and an X-linked recessive type have also been described. Generally, autosomal dominant phenotypes are rather less severe and demonstrate widely variable expressivity and incomplete penetrances. On the other hand, autosomal recessive syndactylies are clinically more severe with rather consistent phenotypes.

In this communication, first a review of classification schemes proposed by various authors for syndactyly is given. Then, the 'current classification' is presented, which is a revised and extended version of the scheme put forward by Temtamy and McKusick. ${ }^{3}$ It is supported by snapshots of hallmark features as well as examples of clinical and genetic heterogeneity of each syndactyly. Finally, the key questions in syndactyly research, which remain to be answered, have been highlighted.

\section{SYNDACTYLY: APPRECIATION AND DEVELOPMENT OF CLASSIFICATION}

Syndactyly appears in the medical literature under several synonyms. For example, adherent fingers, ${ }^{4}$ fingers coated with common skin, ${ }^{5}$ coherence of fingers, ${ }^{6}$ fingers grown together, ${ }^{3,5}$ fingers knit together, ${ }^{4}$ skin fusion, digits in stocking, ${ }^{7}$ fingers stuck together, ${ }^{8}$ symphalanginae, symphalangus syndactylous, ${ }^{9}$ syndactylia, syndactylous ossification, ${ }^{9}$ webbed toes, ${ }^{10}$ and zygodactyly. ${ }^{11}$ The earliest appreciation of syndactyly as a birth anomaly or burn-trauma can be traced back to a famous Andalusian surgeon in the middle ages named Al-Zahrawi Abulcasis (936-1013). ${ }^{12,13}$ Ambroise Pare (1510-1590) in the sixteenth century described syndactyly as fingers stuck together and polydactyly as superfluous fingers, respectively. ${ }^{8,4}$ Thus, it was established quite early that webbed fingers are not infrequent, appear in various forms, usually without the involvement of other organ systems but frequently witnessed with extra digits (Bell ${ }^{4}$ and references therein). Minor webbing types could be easily overlooked; however, severe types 
Table 1 Classification schemes proposed for syndactylies

\begin{tabular}{|c|c|c|}
\hline Author & Syndactyly type identified & Description \\
\hline \multicolumn{3}{|l|}{ Anatomical approach } \\
\hline Roblot $(1906)^{14}$ & Complete vs partial & Based on the extent of webbing; also observed syndromic vs non-syndromic \\
\hline Weidenreich (1923) ${ }^{11}$ & Zygodactyly & Identified two types for $2 / 3$ toes webbing; partial vs complete; and common vs rare type \\
\hline Bell $(1953)^{4}$ & $\mathrm{~A} 1, \mathrm{~A} 2, \mathrm{~B} 1, \mathrm{C}$; and subgroups & Each type is unique but combination of various types are possible \\
\hline Kelikian $(1974)^{15}$ & One to eight categories & Considers cutaneous/bony fusion, number of involved digits, and other digital insults \\
\hline Woolf and Cone $(1977)^{16}$ & Division of type I (la, Ib) & Type la shows $2 / 3$ toes webbing; type Ib has $2 / 3$ toes; and $3 / 4$ fingers involvement \\
\hline Lenz and Majewski (1981) ${ }^{17}$ & Syndactyly type la & Separated Lueken type from syndactyly type I \\
\hline \multicolumn{3}{|c|}{ Descriptive and embryological classification } \\
\hline Swanson $(1976)^{18}$ & Simple vs complicated & Based on failure of differentiation (separation of digits) \\
\hline Winter and Tickle (1993) 19 & $\begin{array}{l}\text { Pre-, meso-, post-axial, and total } \\
\text { syndactyly types }\end{array}$ & $\begin{array}{l}\text { Based on normal/abnormal patterns and secondary limb modeling during development; } \\
\text { preaxial, mesoaxial, postaxial, and total syndactyly types }\end{array}$ \\
\hline Stoll et al $(1998)^{20}$ & Radial, central, ulnar, complex types & A descriptive system to classify limb defects \\
\hline \multicolumn{3}{|l|}{ Clinical, genetic and molecular approach } \\
\hline Temtamy and McKusick (1978) ${ }^{3}$ & Five types $(\mathrm{I}-\mathrm{V})$ & Based on the combination of fused digits and inheritance pattern \\
\hline Goldstein et al $(1994)^{21}$ & Eight types $(\mathrm{I}-\mathrm{VIII})$ & Extension of Temtamy-McKusick, types VI-VIII were introduced \\
\hline Malik et al $(2004,2005)^{22,23}$ & Nine types $(I-\mid X)$ & Extension of Temtamy-McKusick, recessive type IX syndactyly was introduced \\
\hline Harpf et al (2005) ${ }^{24}$ & Subgroups in type VII & Identified 'spoon hand type' and 'oligodactyly type' within type VII \\
\hline Malik et al $(2005)^{25}$ & Syndactyly type I extended & Four subdivisions proposed for type I syndactyly (I-1 to I-4) \\
\hline Malik et al (2006) 26 & Syndactyly type II extended & Splitting type II syndactyly (SPD1, SPD2, SPD3) \\
\hline Malik and Grzeschik (2008) 27 & Clinical variants in Type II & Identified typical features, minor variants, and unusual phenotypes in type II \\
\hline
\end{tabular}

required surgical corrections. As the number of reports regarding the deformity grew into the medical and anthropological records, it permitted a systematic evaluation of various types. Hence, several attempts were made to classify webbing of digits which, depending upon the approach taken, fall into three categories (summary in Table 1):

\section{Simple anatomical classification systems}

The classical approach has been a simple anatomical categorization depending upon the digits within the web, number of digits involved, and also, the extent of webbing. In this context, the systems introduced by Roblot, ${ }^{14}$ Weidenreich, ${ }^{11}$ Bell, ${ }^{4}$ Kelikian, ${ }^{15}$ and Lenz and Majewski ${ }^{17}$ are worth mentioning (Table 1). Of particular interest is the classification system proposed by Bell ${ }^{4}$ who identified four major types (A1, A2, B1, and C). However, there were types with overlapping features and still others that remained unclassified (reviewed in Malik et $a l^{28}$ ).

\section{Descriptive and embryological approaches of classification}

These approaches rely on the grouping of similar patterns of limb deficiencies due to embryological failures. They consider, for instance, whether the insult involves soft/skeletal tissue or only the dermomyofascial structure. ${ }^{18}$ One of the prime objectives of these classification schemes has been to help adopt best surgical and treatment methods to restore the correct digit number, size of individual rays, and digit shape. ${ }^{29}$ Additionally, these schemes were based on the observations of sporadic cases and post-traumatic syndactylies.

Winter and Tickle ${ }^{19}$ based their classification essentially on the mechanism of pattern formation and secondary modeling of limb bud during development. Hence, they categorized syndactylies as preaxial, mesoaxial, postaxial, and total webbing types (Table 1). A relatively similar scheme was introduced by Stoll et $a^{20}$ by emphasizing more on descriptive nomenclature. The original idea was to introduce the emerging molecular data into the classification system. However, it is not always possible to comprehend all digit malformations on the basis of morphogenesis and gene function. ${ }^{20}$

\section{Clinical and genetic approach}

Temtamy and McKusick ${ }^{3}$ proposed a classification essentially based on the phenotypic presentation (ie, site and nature of digit involvement) as well as the pattern of disease segregation in large families. They identified five discrete and isolated syndactylies, in addition to a few unclassified types (Table 1). Since then it has been the most widely used scheme by the geneticists and clinicians.

\section{CURRENT SYNDACTYLY CLASSIFICATION: CLINICAL, GENETIC, AND MOLECULAR APPROACH}

The Temtamy-McKusick classification has been a well-appreciated scheme for a number of reasons. First, the majority of the reported isolated syndactyly phenotypes in families/subjects can be easily typed with this scheme. ${ }^{28}$ Second, novel syndactyly phenotypes could be easily accommodated by extending the existing classification system. $^{21-23}$ Third, subgroups could be introduced with equal flexibility as fresh dysmorphology data emerged. ${ }^{23,25}$ Fourth, and importantly, the molecular data have been integrated into the classification system without disturbing the original scheme. Finally, the OMIM catalogue, which is the most widely used unified and consolidated dysmorphology resource for geneticists, clinicians, and genetic counselors, adopts this scheme.

The 'current classification scheme' of syndactyly is an adaptation and extension of Temtamy-McKusick system by incorporating into it the clinical, genetic, and molecular developments in this field. The step-by-step progress in this scheme is summarized in Table 1. The syndactyly types identified according to the current classification are described below (Figures 1 and 2; Supplementary Figure 1; Table 2):

\section{Syndactyly type I}

Of all the known non-syndromic syndactylies, type I syndactyly is one of the most common types. It demonstrates mesoaxial webbing: fusion of third and fourth fingers, and/or second and third toes. Several characteristic phenotypic and genetic variants within this type 


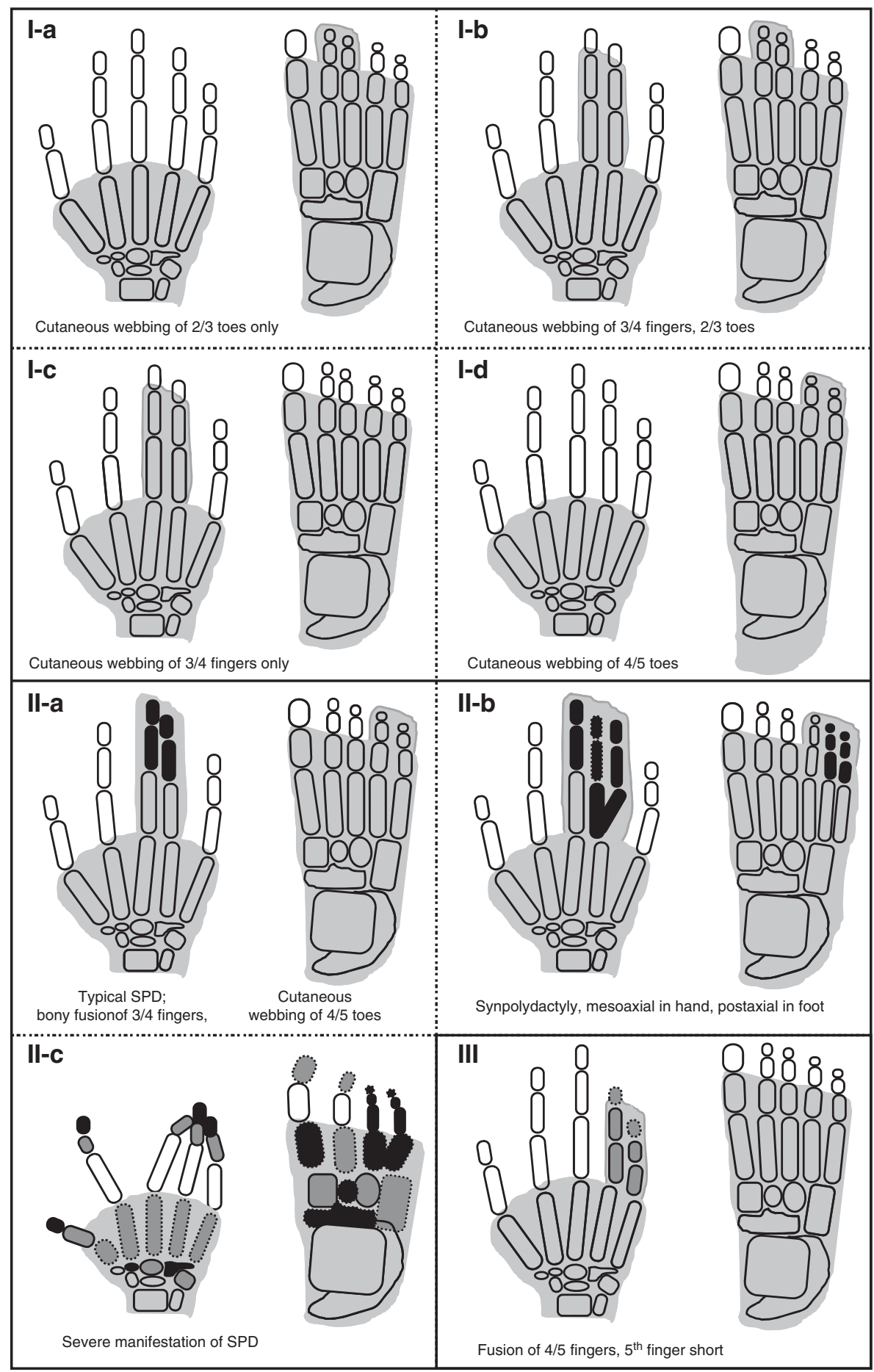

Figure 1 Schematic diagrams of syndactyly types (I-a-III). Shaded digits depict cutaneous fusion only, while bony synostosis is represented by black digital elements within the shaded area. The grey digital elements show hypoplastic phalanges or clinodactyly/brachydactyly. The digital elements with amorphous borders symbolize dysplastic bones (adapted from Malik and Grzeschik). ${ }^{27}$

witnessed in distinct families have led to the suggestion of four subtypes for type I syndactyly (Table 2$)^{25}$

\section{Syndactyly type I-a (Weidenreich type; zygodactyly; 2/3 toes syndactyly)}

This autosomal dominant entity was originally named zygodactyly by Weidenreich. ${ }^{11}$ Zygodactyly is a minor and least conspicuous type, and often goes unnoticed in the clinical practice. It has an estimated prevalence of 4 in 10000 men and accounts for $70 \%$ of all non-syndromic syndactyly cases. ${ }^{2,47}$

Zygodactyly is characterized by bilateral cutaneous webbing of second and third toes without the involvement of hands (Figure 1). Rarely, other toes are also affected. The phenotype in both feet is usually concordant. ${ }^{48}$ In its mildest forms, it gives the impression of slight ascent of interdigital web between second and third toes, or it may only be detected by abnormal dermatoglyphics. ${ }^{3}$ In its extreme 


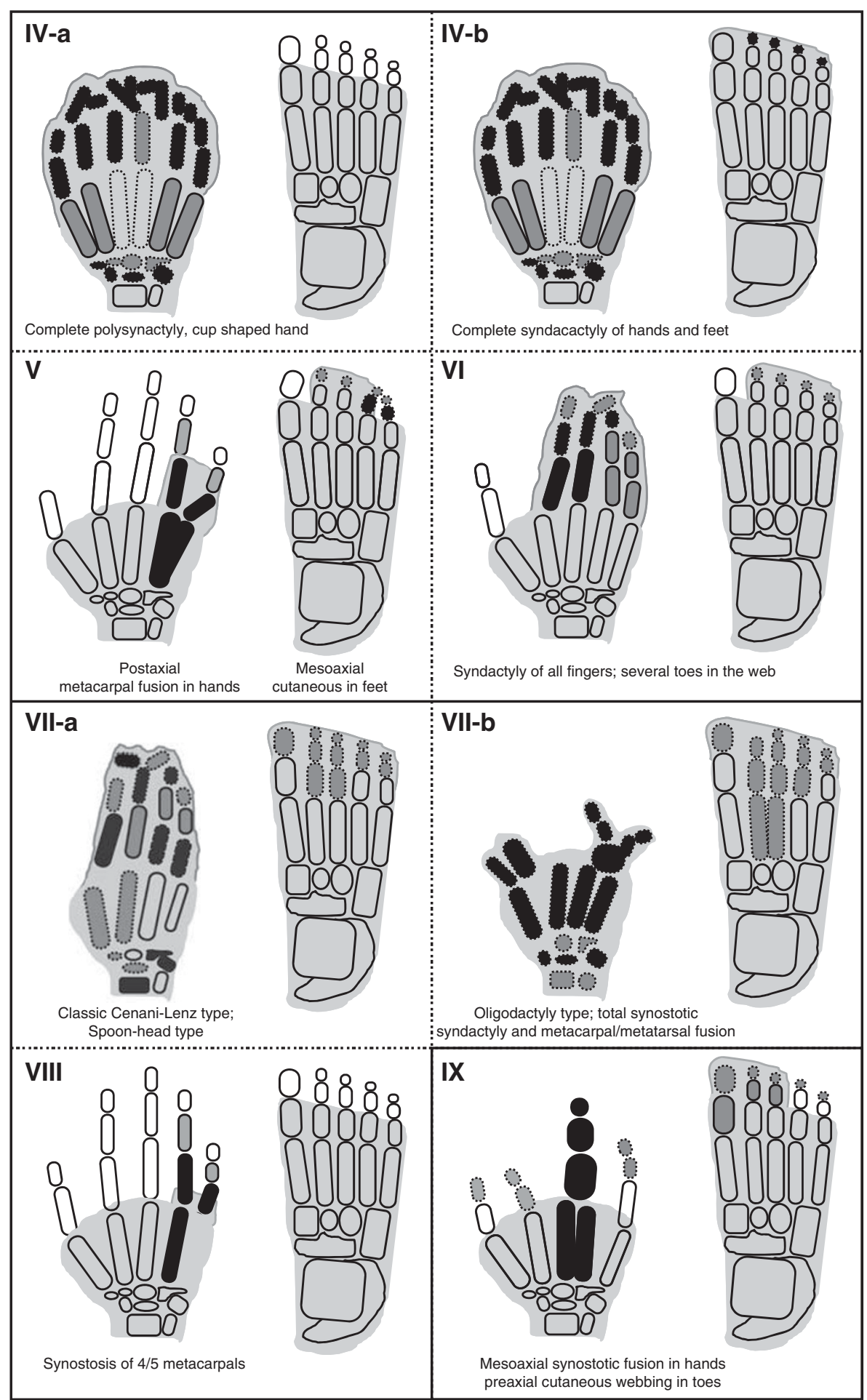

Figure 2 Schematic diagrams of syndactyly types (IV-a-IX).

form, the web reaches up to phalangeal tips, a rather intimate fusion is witnessed at nails, and the second toe depicts varus inclination. ${ }^{25}$ First molecular evidence of zygodactyly being a distinct genetic entity was provided by Malik et $a l^{25}$ by a mapping study on a large Pakistani family. Cosegregation of zygodactyly was shown with ZD1 locus at chromosome 3p21-p31. However, genetic heterogeneity has been suggested from the linkage data of a German kindred. ${ }^{25}$
Syndactyly type I-b (Lueken type; 3/4 fingers and 2/3 toes syndactyly)

This subtype is characterized by bilateral webbing of third and fourth fingers, and second and third toes (Figure 1). Finger's webbing may exhibit osseous fusion in the form of a bony bridge at the phalangeal tips. In more severe cases, additional fingers from second to fifth and toes from first to fifth may be involved. Reduplication of any fused 
Table 2 Current classification of well-characterized syndactyly types

\begin{tabular}{|c|c|c|c|c|c|c|c|}
\hline$I D$ & Type/description & $O M I M$ & Fingers webbing & Toes webbing & Inheritance & Locus/gene & $\begin{array}{l}\text { Key } \\
\text { reference }\end{array}$ \\
\hline I-a & $\begin{array}{l}\text { ZD1; Zygodactyly; } \\
\text { Weidenreich type }\end{array}$ & 609815 & Normal & 2/3 Toes only & $A D$ & $3 p 21.31$ & 25 \\
\hline I-b & SD1; Lueken type & 185900 & 3/4 Fingers, cutaneous/bony & 2/3 Toes, cutaneous & $A D$ & $2 q 34-q 36$ & 30,31 \\
\hline I-C & Montagu type & & 3/4 Fingers only, cutaneous/bony & Normal & $A D$ & & 32 \\
\hline $1-d$ & Castilla type & & Normal & 4/5 Toes only, cutaneous & $A D ?$ & & 2 \\
\hline II-a & SPD1; Vordingborg type & 186000 & SPD, mesoaxial (3/4 fingers) & SPD, postaxial ( $4 / 5$ toes) & $A D$ & 2q31; HOXD13 & 33 \\
\hline II-b & SPD2; Debeer type & 608180 & SPD is central and postaxial & Postaxial syndactyly & $A D$ & 22q13.3; FBLN1 & 34 \\
\hline II-C & SPD3; Malik type & 610234 & SPD is central & SPD postaxial & $A D$ & $14 q 11.2-q 13$ & 26 \\
\hline III & $\begin{array}{l}\text { SDTY3; ODDD; } \\
\text { Johnston-Kirby type }\end{array}$ & 186100 & 4/5 Fingers; fifth finger short & Normal & $A D$ & 6q21-q23; GJA1 & 35 \\
\hline IV-a & SDTY4; Haas type & 186200 & $\begin{array}{l}\text { All fingers webbed; pre-/post-axial } \\
\text { polydactyly, cup-shaped hand }\end{array}$ & Normal & $A D$ & $\begin{array}{l}\text { 7q36; ZRS } \\
(L M B R 1)\end{array}$ & 36,37 \\
\hline IV-b & Andersen-Hansen type & & $\begin{array}{l}\text { All fingers webbed; pre-/post-axial } \\
\text { polydactyly, cup-shaped hand }\end{array}$ & $\begin{array}{l}\text { Variable webbing of toes with } \\
\text { polydactyly }\end{array}$ & & & 38 \\
\hline V & SDTY5; Dowd type & 186300 & $\begin{array}{l}4 / 5 \text { Fingers with metacarpals fusion; } \\
\text { hypoplastic metacarpals } 4 / 5\end{array}$ & Mesoaxial webbing & $A D$ & $2 q 31 ; H O X D 13$ & 39,40 \\
\hline VI & Mitten type & & 2/5 Fingers & 2/5 Toes & $A D$ & & 3 \\
\hline VII-a & $\begin{array}{l}\text { Cenani-Lenz type; } \\
\text { spoon-hand type }\end{array}$ & 212780 & $\begin{array}{l}\text { Total synostotic syndactyly with } \\
\text { metacarpals fusion, spoon-head } \\
\text { shape }\end{array}$ & $\begin{array}{l}\text { Total synostotic syndactyly with } \\
\text { metatarsals fusion }\end{array}$ & AR & $\begin{array}{l}11 \mathrm{p} 12-\mathrm{p} 11.2 \\
\text { LRP4. }\end{array}$ & 41,42 \\
\hline VII-b & Oligodactyly type & & Few deformed digits & Variable syndactyly of toes & $A D$ & $\begin{array}{l}\text { 15q13.3; } \\
\text { GREM1-FMN1 }\end{array}$ & 43 \\
\hline VIII-a & Orel-Holmes type & 309630 & 4/5 Metacarpal fusion & Normal & $X-R$ & & 44,45 \\
\hline VIII-b & Lerch type & & 4/5 Metacarpal fusion & Normal & $A D$ & & 46 \\
\hline IX & MSSD; Malik-Percin type & 609432 & $\begin{array}{l}\text { Mesoaxial synostotic syndactyly with } \\
\text { phlanageal reduction }\end{array}$ & $\begin{array}{l}\text { Preaxial webbing; distal phalan- } \\
\text { geal hypoplasia }\end{array}$ & AR & $17 p 13.3$ & 22,23 \\
\hline
\end{tabular}

Abbreviation: SPD, synpolydactyly.

digit is not a characteristic of this type. In the family reported by Lueken, this dominant phenotype was mapped to the SD1 locus at chromosome $2 \mathrm{q} 34-\mathrm{q} 35$. $^{30,31}$

\section{Syndactyly type I-c (Montagu type; $\mathbf{3 / 4}$ fingers syndactyly)}

This rare autosomal dominant type is characterized by bilateral cutaneous/bony fusion of third and fourth fingers with normal feet (Figure 1). ${ }^{32}$ A large Chinese family reported by $\mathrm{Hsu}^{49}$ had 23 affected subjects demonstrating variable degree of bilateral osseous fusion of third and fourth or third, fourth and fifth fingers. Only one subject also had partial fusion of toes from third to fifth.

\section{Syndactyly type I-d (Castilla type; 4/5 toes syndactyly)}

This subtype depicts bilateral cutaneous webbing of fourth and fifth toes (Figure 1) and has been reported to be the second most common type of isolated webbing of toes with a frequency of 0.22 in 10000 subjects. ${ }^{2}$ Occasionally, the fifth toe is tucked inside the fibular aspects of the fourth toe, and thus any minor form of webbing could be easily overlooked in the clinical practice. This is particularly the case when the fifth toe is disfigured due to faulty footwear. The inheritance pattern and penetrance estimates for this subtype have not been worked out.

\section{Syndactyly type II (Vordingborg type; 3/4 fingers and 2/3 toes} synpolydactyly, SPD)

Type II syndactyly/SPD, a well-described entity, is clinically and genetically one of the most heterogeneous types. The hallmark features of SPD are cutaneous/bony fusion of third and fourth fingers and second and third toes with partial or complete reduplication of a digital ray within the syndactylous web (Figure 1). ${ }^{27}$ It is the only syndactyly type with a mesoaxial superfluous finger. The extreme phenotypic heterogeneity in SPD families has led to the lumping of all clinical variants ( $\sim 18$ types) into three categories: (A) typical SPD features; (B) minor variants; and (C) unusual phenotypes. ${ }^{27}$ SPD segregates as an autosomal dominant entity with reduced penetrance. Three SPD loci have been discovered (SPD1-3), however, these entities have not yet been clinically delineated (Table 2). ${ }^{33,34,26}$ Additionally, detailed clinical and mutation data are available only for SPD1 linked to HOXD13.

\section{Syndactyly type III (Johnston-Kirby type; $4 / 5$ or $3 / 4 / 5$ fingers fusion)}

This type of syndactyly affects fourth and fifth or third, fourth and fifth fingers (Figure 1). The middle phalanx of the fifth finger is hypoplastic. ${ }^{35}$ The fourth finger shows valgus deviation in order to accommodate the webbing with little finger particularly when the fusion is complete. ${ }^{3}$ There is adduction of fused fingers, and the nails of the syndactylyous fingers are fused medially. The fusion may involve a bony bridge at the distal phalanges. The feet are generally unaffected. This type shows an autosomal dominant mode of inheritance with incomplete penetrance.

The fusion of fourth and fifth fingers is, likewise, a feature of ODDD (oculodentodigital dysplasia), which exhibits additional 
symptoms of eyes, ears, and orofacial region. Schrander-Stumpel et $a l^{50}$ proposed that ODDD and pure syndactyly type III are the respective ends of a clinical spectrum as variable expression of a contiguous gene deletion syndrome. Interestingly, molecular studies revealed that type III syndactyly and/or ODDD are caused by mutations in GJA1, a pleiotropic gene encoding connexin $43 .{ }^{51}$

Syndactyly type IV (Haas type; complete syndactyly of all fingers) Haas type syndactyly has a prevalence of $1 / 300000$ and segregates in an autosomal dominant fashion. ${ }^{2}$ It manifests itself as complete cutaneous fusion of all fingers accompanied by the presence of extra digital pre- or postaxial ray(s) in the web (Figure 2). ${ }^{36}$ The nails may be fused completely or give an impression of separation by a groove only. Flexion of fingers is limited and the union of contiguous fingers gives the hand a cup-shaped appearance. Phalanges may fuse as a conglomerate mass of bones; however, metacarpal synostosis is absent.

In the literature, at least two variants of type IV syndactyly have been reported: (a) typical Haas type without involvement of feet; and (b) complete fusion of all fingers with variable fusion of all five digits in feet (Table 2) ${ }^{52}$ Haas type syndactyly has been shown to be allelic to triphalangeal thumb polysyndactyly, which is present at a milder end of phenotype. Both entities are caused by mutations in the $Z R S$ locus at chromosome 7q36 (LMBR1), encompassing a long-range regulator of $\mathrm{SHH}^{38,37}$

\section{Syndactyly type V (Dowd type; fusion of 4/5 metacarpals)}

The hallmark of this type is the fusion of fourth and fifth metacarpals (Figure 2). Additional symptoms may involve shortening of fused fourth and fifth metacarpals, ulnar deviation of fingers from second to fifth, interdigital cleft between third and fourth fingers, camptodactyly of fifth finger, short distal phalanges, and absent distal interphalangeal creases of the affected fingers. ${ }^{39}$ In the feet, there is hyperplasia of first ray/metatarsal, and shortening of metatarsals from second to fifth, resulting in varus deviation of metatarsals and valgus deviation of toes/phalanges. Type V syndactyly is inherited as an autosomal dominant entity, and it has been attributed to a missense mutation in homeodomain of HOXD13 in a Chinese family. ${ }^{40}$

Syndactyly type VI (Mitten type; fusion of 2/5 fingers and 2/3 toes) Temtamy and McKusick ${ }^{3}$ described a family in which the index subject had fusion of fingers from second to fifth in his right hand, whereas distal and terminal phalanges were amalgamated in a knot-like structure (Figure 2). The feet showed syndactyly involving second and third toes. The maternal second cousin also had the same deformity. Other family members, however, showed only webbing between second and third toes without involvement of fingers. An autosomal dominant mode of inheritance with reduced penetrance and variable expressivity has been suggested for this rare type.

\section{Syndactyly type VII (Cenani-Lenz syndactyly, CLS; severe bony fusion of all digits and deformed hand)}

This autosomal recessive entity manifests severe abnormalities of all digital elements. It is characterized by gross disorganization of all bones of hand to such an extent that no phalangeal element is identifiable (Figure 2). ${ }^{41}$ The carpals, metacarpals and phalanges show irregular synostosis giving an impression of 'hands-in-stockings'. The anomaly may involve radius and ulna that are either fused, short, or rudimentary resulting in luxation of the radial head and mesomelic shortening of forearm. ${ }^{3}$ Lower limbs show changes similar to upper limbs and certain digital rays may be absent. Additionally, there is rare involvement of craniofacial and nephrological features. ${ }^{53,42}$
Harpf et al ${ }^{24}$ suggested that there exist two grossly different clinical features in Cenani-Lenz type: (a) spoon-head type, and (b) oligodactyly type (Table 2). They also differentiated between consistent and inconsistent feature for CLS. Recently, Li et al ${ }^{42}$ have shown that CLS, both spoon-head and oligodactyly types, and with or without kidney malformations are caused by mutations in LRP4 (chromosome $11 \mathrm{p} 11.2$ ), which is involved in $\mathrm{Wnt} / \beta$-Catenin signaling. Interestingly, another molecular study showed that Cenani-Lenz phenotype with renal defects and hearing loss, and an autosomal dominant CenaniLenz-like non-syndromic oligodactyly are caused by genomic rearrangements of GREM1-FMN1 locus on chromosome 15q13.3. ${ }^{43}$

\section{Syndactyly type VIII (Orel-Holmes type; metacarpals 4/5 fusion; $\mathrm{X}$-linked recessive)}

It is characterized by the fusion of fourth and fifth metacarpals with a marked ulnar deviation of the little finger and with no other abnormality (Figure 2). There are shortened fourth and fifth metacarpals with excessive separation between their distal ends, and inability to bring the affected fingers in parallel to other fingers. Fifth metacarpal is hypoplastic and tri-radii $\mathrm{c}$ and $\mathrm{d}$ are absent. ${ }^{54,45}$ This entity shows X-linked recessive inheritance. ${ }^{54,44}$ However, there is at least one report depicting autosomal dominant segregation for this phenotype (Table 2). ${ }^{46}$

Syndactyly type IX (Malik-Percin type; fusion of 3/4 metacarpals with a reduction of mesoaxial finger, and preaxial syndactyly of toes)

Percin et $a l^{55}$ and Malik et $a l^{22}$ described a consanguineous Turkish and Pakistani family, respectively, in which the affected subjects showed mesoaxial reduction of fingers, osseous synostosis of third and fourth metacarpals culminating into a single digit, malformed thumbs, and hypoplasia and clinodactyly of the fifth finger (Figure 2). In addition, there was preaxial webbing of toes with terminal phalangeal hypoplasia of all toes. Clinically this type is less severe than CLS as it is not extending beyond carpals/tarsals, and is not characterized by bizarre arrangement of skeletal elements of hand/foot. This entity segregated in autosomal recessive fashion and was mapped to chromosome $17 \mathrm{p} 13.3 .^{23}$

\section{DISCUSSION}

Syndactyly is a failure in the separation of developing digits during organogenesis. Being an explicit limb phenotype, it comes to immediate medical attention at child's birth, particularly when it appears in the upper limbs. The involvement of feet is more frequent than the involvement of hands, and males are affected twice as frequently as females. ${ }^{2,3,56}$

Syndactyly is a common feature of more than 300 hereditary syndromic malformations (OMIM) and it provides additional help in the ascertainment of these malformations (eg, F-syndrome, Apert syndrome, Seathre-Chotezen syndrome) (Supplementary Table 1). Beyond the well-characterized syndactylies that have genetic etiology there are syndactyly types that occur with congenital ring constrictions, that is, acrosyndactyly/pseudosyndactyly. ${ }^{2}$

Typing of syndactyly can be quite puzzling. For instance, intrafamilial and individual-specific clinical variability may result in phenotypic overlap with other entities. Identification of syndactyly is particularly daunting when only few affected individuals are encountered with a particular phenotype, and other occasional digit malformations (ectro-, poly-, brachy-, campto-dactyly, etc) also accompany the syndactylous condition. ${ }^{57}$ Various other factors complicate the understanding and pathomorphology of syndactyly. 
For instance, inheritance pattern, incomplete penetrance, genetic heterogeneity, limited number of families linked to each syndactyly locus (except type II-1 and III), a large number of morphogens involved in limb development, complex interactions between these morphogens, and the involvement of modifier genes and/or long range regulatory elements (eg, $Z R S$ ). For a correct typing in syndactyly (and other developmental anomalies), more weight should be given to the phenotypes in extended families. As a general rule, the most common phenotype in particular kindred is considered important for typing. The involvement of upper and/or lower limbs, webbing pattern, and the ascent of web from phalanges up to metacarpals/ metatarsal and carpals/tarsals are critical for diagnosis.

A workable classification should employ a simple but meticulous and itemized approach. It should allow the recording of common clinical entities with minimal confusion, but yet permit the full categorization of complex cases. ${ }^{20}$ Thus, one approach could be the grouping of malformations according to morphogenesis or to their cause (ie, genes). ${ }^{19}$ However, genes cannot always be used to classify morphogenesis, ${ }^{20}$ owing to the fact that the action of genes is overlapping. Moreover, mutations of different genes can lead to the same phenotype (eg, type II syndactyly). Conversely, mutations in the same gene can lead to different phenotypes (eg, HOXD13). Thus, even after considerable advances in limb morphogenesis and molecular embryology, it is still not possible to precisely correlate a specific syndactyly/ limb anomaly to the underlying gene(s). Hence, the current classification takes the advantage of clinical, genetic, and molecular approaches, simultaneously (Supplementary Figure 1).

Before we can type syndactylies with confidence, there are still a number of intriguing questions that await resolution. For instance, a distorted sex ratio in certain syndactylies is very puzzling. ${ }^{16}$ Large epidemiological surveys in various populations would be helpful in the evaluation of sex distortion and revisiting the prevalence estimates of various syndactyly types. Additionally, it is not known how the same underlying genetic factors may lead to dissimilar webbing in hands and feet. Also, the extreme phenotypic variability observed in certain types (eg, SPD) is difficult to explain on the basis of current genetic and molecular data alone. Furthermore, it is also not clear why certain web types (ie, fusion of second and third toes; third and fourth fingers) are observed more frequently in isolated or syndromic situations. ${ }^{2}$ For syndactylies with known underlying genes, further studies on the allelic mutation series are required to establish genotype-phenotype correlation(s).

The study of syndactyly could contribute substantially in the appreciation of limb developmental pathways. The three main interlocking developmental axis of the growing limb bud are the proximodistal, running in the human arm from shoulder to digits; the anteroposterior (AP), from thumb to the little finger; and dorsoventral, from the back of the hand to the palm. The digit specification and identity are mainly coordinated by the AP developmental axis. ${ }^{58}$ Cutaneous syndactyly may result when the growing digits fail to separate during the late stages of digit sculpting by interdigital necrosis (for instance via BMP pathways). Experimental studies on mice revealed that BMP pathway is necessary for apoptosis in the developing limb and the inhibition of BMP signaling caused extensive soft tissue syndactyly and postaxial polydactyly. ${ }^{59}$ Osseous fusion resulting in more intimate cohesion of digits and the involvement of proximal segments of hand/foot would necessitate gross irregularity in rather early developmental cascades. The identification of novel genes for syndactyly could not only elucidate the limb patterning and digit specification mechanisms but should also help to single out complex interlocking development plans. Finally, syndactyly is a very relevant model to study the interaction of genetic mechanisms, epigenetic events, pleiotropy and stochastic factors, which generate extreme clinical heterogeneity in affected subjects and families. ${ }^{60}$ The present review of classification of syndactyly would be helpful in the appreciation of syndactyly malformation and defining its affinities with other digit anomalies like polydactyly, oligodactyly, and brachydactyly.

\section{CONFLICT OF INTEREST}

The author declares no conflict of interest.

\section{ACKNOWLEDGEMENTS}

The helpful comments of Professors Karl-Heinz Grzeschik, Nurten Akarsu and Mahmud Ahmad are highly acknowledged. The study was supported by Higher Education Commission Pakistan, and Pakistan Science Foundation, Islamabad.

\section{WEB SOURCES}

OMIM. Online Mendelian Inheritance in Man. http://www.ncbi.nlm.nih.gov/ omim/.

Decipher. http://decipher.sanger.ac.uk/.

1 Hay S: Incidence of selected congenital malformations in lowa. Am J Epidemiol 1971; 94: 572-584.

2 Castilla EE, Paz JE, Orioli-Parreiras IM: Syndactyly: frequency of specific types. Am J Med Genet 1980; 5: 357-364.

3 Temtamy SA, McKusick VA: Syndactyly. In: The Genetics of Hand Malformations. New York: Alan R Liss, 1978; 301-322.

4 Bell J: On syndactylies and its association with polydactyly. In: The Treasury of Human Inheritance. London: Cambridge University Press, 1953; V(II): 30-50.

5 Koenner DM: Abnormalities of the hand and feet. J Hered 1934; 25: 329-334.

6 Davis JS, German WJ: Syndactylism coherence of the fingers or toes. Arch Surg 1930; 21: 32-75.

7 Schultz AH: Zygodactyly and its inheritance. J Hered 1922; 13: 113-117.

8 Lubahn JD: Syndactyly. in Fitzgerald RH, Kaufer H, Malkani AL (eds): Orthopaedics. Philadelphia: Elsevier Health Sciences, 2002; 1895-1896.

9 Straus WL: The nature and inheritance of webbed toes in man. J Morphol Physiol 1926; 41: 427-439.

10 Newsholme HP: A pedigree showing bi-parental inheritance of webbed toes. Lancet 1910; 176: 1690-1691.

11 Weidenreich F: Die Zygodactylie und ihre Vererbung. Z Abst Vererb 1923; 32: 304.

12 Spink MS, Lweis GL: Albucasus on surgery and instruments. The Wellcome Institute for History of Medicine. London, 1973.

13 Al-Ghazal SK: Al-Zahrawi (Albucasis) - a light in the dark middle ages in Europe. $\mathrm{J}$ Int Soc Hist Islam Med 2003; 1: 37-38.

14 Roblot G: La syndactylie conge'nitale. Paris: Maulde, Doumencet Cie, 1906.

15 Kelikian H: Congenital Deformities of the Hand and Forearm. Philadelphia: WB Saunders Company, 1974.

16 Woolf CM, Cone DL: Problem of sex ratio in cases of type I syndactyly. J Med Genet 1977; 14: 108-113.

17 Lenz W, Majewski F: Fehlbildungen der Gliedmaßen. in Schinz HR (eds): Lehrbuch der Röntgendiagnostik. Verlag, Stuttgart: Thieme, 1981; 935-1032.

18 Swanson AB: A classification for congenital limb malformations. J Hand Surg Am 1976; 1: 8-22.

19 Winter RM, Tickle C: Syndactylies and polydactylies: embryological overview and suggested classification. Eur J Hum Genet 1993; 1: 96-104.

20 Stoll C, Duboule D, Holmes LB et al: Classification of limb defects. Am J Med Genet 1998; 77: 439-441.

21 Goldstein DJ, Kambouris M, Ward RE: Familial crossed polysyndactyly. Am J Med Genet 1994; 50: 215-223.

22 Malik S, Arshad M, Amin-Ud-Din M et al: A novel type of autosomal recessive syndactyly: clinical and molecular studies in a family of Pakistani origin. Am J Med Genet 2004; 126: 61-67.

23 Malik S, Percin FE, Ahmad W et al: Autosomal recessive mesoaxial synostotic syndactyly with phalangeal reduction maps to chromosome 17p13.3. Am J Med Genet 2005; 134: 404-408.

24 Harpf C, Pavelka M, Hussl H: A variant of Cenani-Lenz syndactyly (CLS): review of the literature and attempt of classification. Br J Plast Surg 2005; 58: 251-257.

25 Malik S, Schott J, Ali SW et al: Evidence for clinical and genetic heterogeneity of syndactyly type I: the phenotype of second and third toe syndactyly maps to chromosome 3p21.31. Eur J Hum Genet 2005; 13: 1268-1274.

26 Malik S, Abbasi AA, Ansar M et al: Genetic heterogeneity of synpolydactyly: a novel locus SPD3 maps to chromosome 14q11.2-q12. Clin Genet 2006; 69: 518-524.

27 Malik S, Grzeschik KH: Synpolydactyly: clinical and molecular advances. Clin Genet 2008; 73: 113-120 
28 Malik S, Ahmad W, Grzeschik KH et al: A simple method for characterising syndactyly in clinical practice. Genet Couns 2005; 16: 229-238.

29 Foucher G, Navarro R, Medina J et al: Metacarpal synostosis: a simple classification and new treatment technique. Plast Reconstr Surg 2001; 108: 1225-1234.

30 Lueken KG: Über eine Familie mit Syndaktylie. Z Menschl Vererb Konstituts/ 1938; 22: $152-159$

31 Bosse K, Betz RC, Lee Y-A et al: Localization of a gene for syndactyly type 1 to chromosome 2q34-q36. Am J Hum Genet 2000; 67: 492-497.

32 Montagu MFA: A pedigree of syndactylism of the middle and ring fingers. Am J Hum Genet 1953; 5: 70-72.

33 Muragaki $\mathrm{Y}$, Mundlos S, Upton J et al: Altered growth and branching patterns in synpolydactyly caused by mutations in HOXD13. Science 1996; 272: 548-551.

34 Debeer P, Schoenmakers EF, Twal WO et al: The fibulin-1 gene (FBLN1) is disrupted in a t $(12 ; 22)$ associated with a complex type of synpolydactyly. J Med Genet 2002; 39: 98-104.

35 Johnston O, Kirby Jr VV: Syndactyly of the ring and little finger. Am J Hum Genet 1955; 7: 80-82.

36 Haas SL: Bilateral complete syndactylism of all fingers. Am J Surg 1940; 50: 363-366.

37 Wieczorek D, Pawlik B, Li Y, Akarsu NA et al: A specific mutation in the distant sonic hedgehog (SHH) cis-regulator (ZRS) causes Werner mesomelic syndrome (WMS) while complete ZRS duplications underlie Haas type polysyndactyly and preaxial polydactyly (PPD) with or without triphalangeal thumb. Hum Mutat 2010; 31: 81-89.

38 Wu L, Liang D, Niikawa N et al: A ZRS duplication causes syndactyly type IV with tibial hypoplasia. Am J Med Genet 2009; 149A: 816-818.

39 Dowd CN: Cleft hand: a report of a case successfully treated with the use of periosteal flaps. Ann Surg 1896; 24: 210.2-21216.

40 Zhao X, Sun M, Zhao J et al: Mutations in HOXD13 underlie syndactyly type V and a novel brachydactyly-syndactyly syndrome. Am J Hum Genet 2007; 80: 361-371.

41 Cenani A, Lenz W: Totale Syndaktylie und totale radioulnare Synostose bei zwei Brüdern. Ein Beitrag zur Genetik der Syndaktylien. Ztschr Kinderheilk 1967; 101: 181-190.

42 Li Y, Pawlik B, Elcioglu N et al: LRP4 mutations alter Wnt/beta-catenin signaling and cause limb and kidney malformations in Cenani-Lenz syndrome. Am J Hum Genet 2010; 86: 696-706

43 Dimitrov BI, Voet $\mathrm{T}$, De Smet $\mathrm{L}$ et al: Genomic rearrangements of the GREM1-FMN1 locus cause oligosyndactyly, radio-ulnar synostosis, hearing loss, renal defects syndrome and Cenani-Lenz-like non-syndromic oligosyndactyly. J Med Genet 2010; 47: 569-574.

44 Orel H: Kleine Beitrage zur Vererbunswissenschaft. 1. Polydaktylie. Z Konstit-Lehre 1928; 13: 691-698.

45 Anneren G, Amilon A: X-linked recessive fusion of metacarpals $|V|$ and $V$ and hypoplastic metacarpal V. Am J Med Genet 1994; 52: 248-250.

46 Lerch H: Erbliche Synostosen der Ossa metacarpalia IV und V. Z Orthop 1948; 78 : $13-16$.

47 Schurmeier HL: Congenital deformities in drafted men. Am J Phys Anthropol 1922; 5: 51-60.

48 Stiles KA, Hawkins DA: The inheritance of zygodactyly. J Hered 1946; 37: 16-18.

49 Hsu CK: Hereditary syndactylia in a Chinese family. Chin Med J 1965; 84: 482-485.

50 Schrander-Stumpel CT, De Groot-Wijnands JB, De Die-Smulders C et al: Type III syndactyly and oculodentodigital dysplasia: a clinical spectrum. Genet Couns 1993; 4: 271-276.

51 Paznekas WA, Boyadjiev SA, Shapiro RE et al: Connexin 43 (GJA1) mutations cause the pleiotropic phenotype of oculodentodigital dysplasia. Am J Hum Genet 2003; 72: 408-418.

52 Andersen HJ, Hansen AK: Tibial hypo-/aplasia with preaxial syn- and polydactyly. Arch Orthop Trauma Surg 1990; 109: 231-233.

53 Temtamy SA, Ismail S, Nemat A: Mild facial dysmorphism and quasidominant inheritance in Cenani-Lenz syndrome. Clin Dysmorphol 2003; 12: 77-83.

54 Holmes LB, Wolf E, Miettinen OS: Metacarpal 4-5 fusion with X-linked recessive inheritance. Am J Hum Genet 1972; 24: 562-568.

55 Percin EF, Percin S, Egilmez $\mathrm{H}$ et al: Mesoaxial complete syndactyly and synostosis with hypoplastic thumbs: an unusual combination or homozygous expression of syndactyly type I? J Med Genet 1998; 35: 868-874.

56 Temtamy SA: Genetic Factors in Hand Malformations. PhD Dissertation. Baltimore, MD, USA: The Johns Hopkins University, 1966.

57 Elliott AM, Reed AH, Evans JA: Central ray deficiency with extensive syndactyly: a dilemma for classification. Genet Couns 2009; 20: 27-43.

58 Towers M, Tickle C: Growing models of vertebrate limb development. Development 2009; 136: 179-190.

59 Guha U, Gomes WA, Kobayashi T et al: In vivo evidence that BMP signaling is necessary for apoptosis in the mouse limb. Dev Biol 2002; 249: 108-120.

60 Wilkie AO: Why study human limb malformations? J Anat 2003; 202: 27-35.

Supplementary Information accompanies the paper on European Journal of Human Genetics website (http://www.nature.com/ejhg) 